\title{
DESENVOLVIMENTO E PRODUTIVIDADE DO MILHO BRS GORUTUBA SOB DIFERENTES LÂMINAS DE IRRIGAÇÃO E ADUBAÇÃO ORGÂNICA
}

\author{
Roseli Freire de Melo ${ }^{1}$, Anderson Ramos de Oliveira² ${ }^{\text {, Welson Lima Simões }}{ }^{3}$ e Mercia Luciana de Souza Santos ${ }^{4}$ \\ ${ }^{1}$ Pesquisadora da Embrapa Semiárido, Rodovia BR-428, Km 152, Zona Rural, CP 23, CEP: 56302-970, Petrolina, PE, \\ roseli.melo@embrapa.br; ${ }^{2}$ Pesquisador da Embrapa Semiárido, Rodovia BR-428, Km 152, Zona Rural, CP 23, CEP: 56302- \\ 970, Petrolina, PE, anderson.oliveira@embrapa.br; ${ }^{3}$ Pesquisador da Embrapa Semiárido, Rodovia BR-428, Km 152, Zona \\ Rural, CP 23, CEP: 56302-970, Petrolina, PE, welson.simoes@embrapa.br, ${ }^{4}$ Licenciatura em Ciências Biológicas, UPE \\ Campus Petrolina, Rodovia BR-203, Km 2, s/n, Vila Eduardo, CEP: 56328-903, Petrolina, PE, mercialuciana@ bol.com.br.
}

RESUMO - O desenvolvimento e a produtividade do milho em regiões semiáridas dependem principalmente da disponibilidade hídrica e da fertilização do solo. O objetivo deste trabalho foi avaliar o efeito de diferentes lâminas de irrigação na presença e ausência de esterco caprino no desenvolvimento e no potencial produtivo do milho BRS Gorutuba em condições semiáridas. $\mathrm{O}$ delineamento experimental adotado foi em blocos casualizados num esquema de parcelas subdivididas, sendo as parcelas representadas por quatro níveis de água, com base na evapotranspiração da cultura (ETc): 30; 60; 90; e 120\% e as subparcelas representadas pela presença ou ausência de esterco caprino, com quatro repetições. Aos 69 dias (milho verde) e 100 dias após o plantio (milho seco) foram avaliadas as variáveis de desenvolvimento e de produtividade da cultura. No milho verde, a altura de plantas aumentou com a maior disponibilidade hídrica do solo. O diâmetro do colmo e a produtividade de espigas, na presença de esterco caprino, aumentaram com a reposição hídrica. Os maiores valores de biomassa fresca e seca da parte aérea foram alcançados com o aumento da lâmina aplicada, na presença de esterco. No milho seco, a produtividade de espigas com palha e sem palha, a produtividade de grãos e o peso de 100 grãos tendem a aumentar com maiores reposições hídricas, independentemente da presença de esterco. A aplicação de lâminas de irrigação e a adubação com esterco caprino influenciam de forma positiva os componentes de crescimento e de produção da cultivar de milho BRS Gorutuba, apresentando valores de produtividade superiores aos encontrados em áreas dependentes de chuva no semiárido.

PALAVRAS-CHAVE: Eficiência no uso da água. Zea mays L. Esterco caprino. Semiárido.

ABSTRACT - The development and yield of maize in semiarid regions depends mainly on water availability and soil fertilization. The objective of this work was to evaluate the effect of different dephts water on the presence and absence of goat manure in the development and productive potential of BRS Gorutuba maize under semiarid conditions. The experimental design was randomized blocks in a subdivided plot scheme, and the plots were represented by four water levels, based on crop evapotranspiration (ETc): 30; 60; 90; and 120\% and the subplots represented by the presence or absence of goat manure, with four replicates. At 69 days (green corn) and 100 days after planting (dry corn) the development and yield variables of the crop were evaluated. In green maize, plant height increased with higher soil water availability. The stalk diameter and ear yield, in the presence of goat manure, increased with water replenishment. The highest values of fresh and dry shoot biomass were reached with the increase of the applied water replenishment, in the presence of manure. In the case of dry maize, yield of ears with and without straw, yield of grains and weight of 100 grains tend to increase with higher water replenishment, regardless of the presence of manure. The application of irrigation levels and fertilization with goat manure positively influence the growth and yield components of the BRS Gorutuba maize crop, presenting productivity values higher than those found in areas dependent on rainfall in the semiarid region.

KEYWORDS: Efficiency in water use. Zea mays L. Goat manure. Semiarid. 


\section{INTRODUÇÃO}

O milho (Zea mays L.) é uma das principais commodities agrícolas do Brasil. Esta cultura apresenta elevado valor econômico e social, notadamente para as comunidades de menor poder aquisitivo, uma vez que se constitui em importante fonte de carboidratos, fibras, minerais e vitaminas. Os grãos de milho podem ser consumidos in natura, com destaque para o milho verde, amplamente comercializado nas praias de todo o litoral brasileiro e no período de festas juninas ou pode ser processado na forma de fubás e farinhas, sendo utilizado em diversos pratos da culinária. Outro aspecto relevante da cultura do milho é sua utilização na fabricação de ração a fim de atender, principalmente, aos segmentos da avicultura e da suinocultura brasileira.

Os maiores produtores deste cereal são os Estados Unidos, China e Brasil. No Brasil, o milho constitui-se na segunda maior cultura de grãos, estando apenas atrás da cultura da soja. De acordo com dados da Companhia Nacional de Abastecimento - CONAB, a produção de milho na safra de 2016/2017 atingiu o patamar de 97,8 milhões de toneladas, com produtividade média de $5.560 \mathrm{~kg} \mathrm{ha}^{-1}$ em uma área estimada de 17,6 milhões de hectares (CONAB, 2017). A produtividade média é variável entre os estados, sendo que os estados da região Sul apresentam as maiores produtividades (superiores a $6.500 \mathrm{~kg} \mathrm{ha}^{-1}$ ); em alguns estados da região Sudeste como o Rio de Janeiro e o Espírito Santo, as produtividades são inferiores à média nacional $\left(2.500 \mathrm{~kg} \mathrm{ha}^{-1}\right) \mathrm{e}$ as menores produtividades são observadas nos estados da região Nordeste, onde a maioria não atinge $1.000 \mathrm{~kg} \mathrm{ha}^{-1}$.

Neste contexto é importante considerar as características edafoclimáticas do Semiárido brasileiro, o qual apresenta regime de precipitação pluviométrica irregular no tempo e no espaço, sendo que as chuvas ocorrem em apenas quatro meses em diversos municípios, com elevadas taxas evapotranspirométricas, solos rasos com baixa fertilidade e de baixa capacidade de retenção de água, além de outros fatores de ordem estrutural e socioeconômica, tornando a agricultura dependente de chuva uma atividade de risco, com consequências graves para a sobrevivência das famílias dos agricultores. Assim, nas condições semiáridas, como as que ocorrem na região Nordeste e no norte dos estados de Minas Gerais e Espírito Santo, uma alternativa para aumentar o potencial de sucesso da atividade é a utilização da irrigação na cultura. Todavia, o manejo da irrigação deve primar pela eficiência no uso da água, a qual relaciona a produtividade da cultura com a quantidade de água requerida na produção durante os processos fisiológicos (KATERJI et al., 2008; SADRAS et al., 2011; ZHUO e HOEKSTRA, 2017). Desta forma, a eficiência pode estar relacionada à quantidade mínima para se obter uma boa produtividade, ao fornecimento adequado de água nos períodos de maior demanda hídrica da cultura e ao sistema de irrigação adotado.

Além de um sistema eficiente no uso da água, outra tecnologia já bem conhecida dos agricultores familiares é a utilização de adubação orgânica, a qual favorece a germinação, o desenvolvimento e aumenta a produtividade da cultura (MELO et al., 2009). De acordo com Pereira et al. (2013), os adubos orgânicos contribuem para a melhoria das propriedades físicoquímicas e biológicas do solo, sendo recomendado seu uso na agricultura. Dentre as vantagens da utilização de adubos orgânicos, citam-se: aumento no teor de matéria orgânica do solo; maior disponibilidade de nutrientes para as plantas, maior aeração do solo, maior diversidade e maior atividade microbiana, aumento da macrofauna, aumento da capacidade de armazenamento de água no solo e redução na temperatura do mesmo, maior acúmulo de $\mathrm{C}$ e $\mathrm{N}$, favorecimento de nodulação de raízes, menor lixiviação de nutrientes, dentre outras (PEREIRA et al., 2013; RONG et al., 2016; ARGAW, 2017).

No Nordeste brasileiro, o esterco caprino constitui-se em uma importante fonte de adubo orgânico, uma vez que a caprinocultura é uma atividade tradicional na região e de grande destaque nacional, com rebanho de mais de nove milhões de cabeças, correspondendo 
a mais de $93 \%$ do rebanho nacional de caprinos (IBGE, 2016). A utilização do esterco caprino na adubação de culturas tem reduzido significativamente o custo da produção, principalmente, na agricultura familiar. De acordo com Melo et al. (2009), o esterco caprino contribui para melhorar a fertilidade do solo ao aumentar os teores de potássio e magnésio e aumentar significativamente o teor de fósforo em até 200\%. Freitas et al. (2012) também observaram efeitos positivos da adubação do solo com esterco caprino ao constatarem que a liberação de fósforo aumentou com o tempo de incorporação do esterco, sendo mais acentuado se incorporado nas camadas de 30 a $40 \mathrm{~cm}$.

Em ambientes de maior fragilidade, a integração de tecnologias que possam potencializar a expressão da máxima produtividade da cultura torna-se necessária, no qual a adoção de cultivares mais adaptadas é recomendável. No caso do milho, a cultivar BRS Gorutuba, por apresentar ciclo superprecoce, é uma alternativa para o plantio durante o curto período chuvoso que ocorre no semiárido. Segundo Carvalho et al. (2010), esta cultivar é adequada para ser cultivada nas regiões semiáridas e para a agricultura de subsistência e de baixo investimento. A BRS Gorutuba pode atingir o florescimento sete dias antes das variedades precoces, com maturação fisiológica antecipada em até 20 dias e produtividades que podem variar de 3.300 a $6.500 \mathrm{~kg} \mathrm{ha}^{-1}$ dependendo das condições edafoclimáticas e de manejo da cultura.

Assim, o objetivo deste trabalho foi avaliar o efeito de diferentes lâminas de irrigação na presença e ausência de esterco de caprino no desenvolvimento e produtividade do milho cultivar BRS Gorutuba.

\section{MATERIAL E MÉTODOS}

O experimento foi conduzido numa barragem subterrânea localizada no Campo Experimental da Embrapa Produtos e Mercados, em Petrolina, PE, cujas coordenadas geográficas são $09^{\circ} 54^{\prime}$ de latitude Sul e $40^{\circ} 29^{\prime}$ de longitude Oeste e altitude de $365,5 \mathrm{~m}$. A região se caracteriza pelo clima semiárido, com temperaturas médias elevadas $\left(23\right.$ a $\left.27{ }^{\circ} \mathrm{C}\right)$, precipitação escassa (500 mm anuais), mal distribuída e concentrada em poucos meses do ano (dezembro a março) e umidade relativa média do ar de 50\% (MOURA et al., 2007).

As condições climáticas foram monitoradas durante todo o experimento, sendo constatada temperatura média do ar de $28,26{ }^{\circ} \mathrm{C}$, com média das máximas de $35,16{ }^{\circ} \mathrm{C}$ e média das mínimas de $22,0^{\circ} \mathrm{C}$, umidade relativa média de $45,61 \%$ e precipitação de $5 \mathrm{~mm}$.

O solo da área experimental é caracterizado como Latossolo Vermelho Amarelo, com textura média. Foram coletadas amostras de solo antes da instalação do experimento, nas profundidades de $0-20 \mathrm{~cm}$, a fim de determinar as características químicas. As amostras de solo e do esterco de caprino (seco e curtido naturalmente ao ar livre), utilizado no experimento, foram conduzidas ao Laboratório de Água e Solo da Embrapa Semiárido, onde foram submetidas à análise conforme metodologia recomendada pela Embrapa (DONAGEMA et al., 2011), cujos resultados se encontram na Tabela 1.

Tabela 1. Características químicas do solo da área experimental e do esterco caprino utilizado, Petrolina-PE.

\begin{tabular}{|c|c|c|c|c|c|c|c|c|c|c|c|c|c|c|c|c|}
\hline Amostras & MO & $\mathbf{C}$ & pH & CE & $\mathbf{P}$ & $\mathbf{C} / \mathbf{N}$ & $\mathbf{N}$ & $\mathbf{K}$ & $\mathrm{Ca}^{2+}$ & $\mathrm{Mg}^{2+}$ & $\mathrm{Na}^{+}$ & $\mathbf{A l}^{3+}$ & $\mathbf{H}+\mathrm{Al}^{3+}$ & SB & CTC & $\mathbf{V}$ \\
\hline \multirow{2}{*}{$\begin{array}{c}\text { Solo } \\
(0-20 \mathrm{~cm})\end{array}$} & $\mathrm{g} \mathrm{kg}^{-1}$ & \multicolumn{7}{|c|}{ 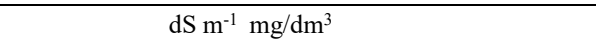 } & \multicolumn{6}{|c|}{ 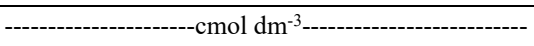 } & & $\%$ \\
\hline & 2,9 & - & 5,0 & 0,79 & 0,6 & - & - & 0,32 & 1,0 & 0,50 & 0,05 & 0,00 & 5,0 & 1,9 & 6,8 & 27,4 \\
\hline \multirow{2}{*}{$\begin{array}{l}\text { Esterco } \\
\text { caprino }\end{array}$} & $----g$ & $n^{-3}--$ & & & \multicolumn{12}{|c|}{----------------g kg } \\
\hline & 508 & 298 & 8,5 & 0,68 & 1,9 & $23: 1$ & 12,97 & 4,86 & 7,1 & 6,30 & & & & & & \\
\hline
\end{tabular}

Utilizou-se o delineamento de blocos casualizados com oito tratamentos e quatro repetições, em parcelas subdivididas, no espaçamento $0,50 \mathrm{~m} \mathrm{x} 1,0 \mathrm{~m}$, contendo duas plantas por cova, com população de 40.000 plantas/hectare da variedade de milho BRS Gorutuba. Os 
tratamentos originaram-se da combinação de quatro níveis de água, com base na evapotranspiração da cultura (ETc): L1-30\%; L2-60\%; L3-90\%; L4-120\% (parcela), tendo como subparcela duas doses de adubo orgânico (presença ou ausência de esterco caprino). O plantio da cultivar foi realizado manualmente em agosto de 2015 (período seco), depositandose seis sementes por cova. Aos oito dias após a emergência realizou-se desbaste, deixando-se duas plantas por cova.

A parcela experimental foi constituída por quatro linhas de plantio de $50 \mathrm{~m}$ de comprimento, totalizando 244 covas, e as subparcelas de quatro linhas de $14 \mathrm{~m}$ de comprimento (68 covas). Na colheita, a primeira e segunda fileira da esquerda para a direita foram colhidas para avaliar a produção de milho verde. A terceira e quarta fileiras foram deixadas para avaliar a produção de grãos.

As subparcelas fertilizadas receberam dois litros de esterco caprino por metro linear $(0,8 \mathrm{~kg})$, equivalente a aplicação de $6.250 \mathrm{~kg} \mathrm{ha}^{-1}$. A aplicação das lâminas de irrigação foi realizada até os 69 dias após o plantio, época de colheita do milho verde (Tabela 2), considerando o coeficiente de cultivo (Kc) indicado por SOUZA et al. (2010) para o milho no semiárido nas diferentes fases de desenvolvimento da cultura: Fase I germinação/emergência, Fase II - crescimento/desenvolvimento, fase III floração/enchimento de grãos e fase IV - maturação fisiológica (ALLEN et al., 2006). A partir deste momento a irrigação foi suspensa, sendo a colheita final (milho seco) realizada aos 100 dias após o plantio.

Tabela 2. Lâminas totais de água aplicadas nas diferentes fases fenológica da cultura do milho BRS Gorutuba, Petrolina-PE, 2015.

\begin{tabular}{cccccc}
\hline \multirow{2}{*}{ Lâminas } & \multicolumn{3}{c}{ Coeficiente de Cultivo (Kc) } & \multirow{2}{*}{ Lâminas totais (mm) } \\
\cline { 2 - 5 } & Fase I & Fase II & Fase III & Fase IV & \\
\hline $30 \%$ da ETc & $\mathbf{0 , 8 7}$ & $\mathbf{1 , 2 1}$ & $\mathbf{1 , 2 1}$ & $\mathbf{0 , 6 1}$ & 139,85 \\
$60 \%$ da ETc & 45,81 & 119,66 & 92,03 & 22,20 & 279,71 \\
$90 \%$ da ETc & 68,72 & 179,48 & 138,05 & 33,30 & 419,56 \\
$120 \%$ da ETc & 91,63 & 239,31 & 184,07 & 44,41 & 559,41 \\
\hline $\mathrm{N}^{0}$ dias* & 15 & 26 & 20 & 9 & 70 \\
\hline
\end{tabular}

*Número de dias considerados nas diferentes fases de desenvolvimentos para aplicação das lâminas; Fase I Germinação/emergência, Fase II - crescimento/desenvolvimento, fase III - floração/enchimento de grãos e fase IV - maturação fisiológica (ALLEN et al., 2006).

O sistema de irrigação adotado foi o gotejamento, com espaçamento de $0,50 \mathrm{~m}$ e vazão de $2 \mathrm{~L} \mathrm{~h}^{-1}$. Após a germinação, as plantas foram irrigadas seguindo os diferentes níveis de lâminas de água. As lâminas de irrigação aplicadas foram calculadas de acordo com a ETc (ETo* $\mathrm{Kc} * \mathrm{Kl})$, medida no período entre as irrigações, de acordo com a eficiência de aplicação de água do sistema e as lâminas de irrigação testadas, conforme a Equação 1.

$$
L i=\frac{(E T o * K c * K l)-P}{E f} * \% E T c
$$

Em que:

Li - Lâmina de irrigação (mm);

ETo - Evapotranspiração medida no período (mm);

Kc - Coeficiente de cultivo da cultura;

$\mathrm{Kl}$ - Coeficiente de localização;

$\mathrm{P}$ - Precipitação medida no período $(\mathrm{mm})$;

Ef - Eficiência do sistema de irrigação $(0,9)$;

\% ETc - Lâmina de irrigação testada, decimal. 
Os valores de ETo foram obtidos de uma estação meteorológica instalada próximo ao local do experimento e para determinação do $\mathrm{Kl}$ médio, utilizou-se a média de quatro valores de coeficiente de localização (Kl), segundo diversos autores, citados por Pizarro (1996), que dependem do valor da fração de área sombreada pelo cultivo de acordo com o desenvolvimento das plantas.

A precipitação de apenas cinco milímetros ocorrida durante todo o período experimental foi desconsiderada nos cálculos das lâminas. Todos os tratamentos, exceto o L120, apresentaram lâminas totais abaixo dos limites recomendados para a cultura do milho que variam entre 500 e 800 mm, conforme Doorenbos e Kassan (1994).

Quanto aos tratos culturais, foram realizadas quatro capinas manuais. Realizou-se, ainda, o monitoramento fitossanitário da cultura, não se observando a presença de pragas ou doenças.

\subsection{AVALIAÇÃO DO MILHO VERDE E MILHO SECO}

Aos 69 dias após o plantio (DAP) foram avaliadas, em de seis plantas por subparcela, as variáveis: altura de planta $(\mathrm{m})$, diâmetro do colmo $(\mathrm{mm})$, produtividade de biomassa fresca e seca da parte aérea $\left(\mathrm{kg} \mathrm{ha}^{-1}\right)$ e produtividade de espiga verde com palha $\left(\mathrm{kg} \mathrm{ha}^{-1}\right)$. A altura foi determinada com auxílio de uma trena graduada em centímetros, considerando a distância entre o nível do solo até a última folha totalmente expandida. O diâmetro do colmo foi determinado a cinco centímetros do nível da superfície do solo, utilizando-se um paquímetro digital. Realizou-se a colheita das espigas de milho verde, sendo que estas foram pesadas em balança digital para aferição da biomassa de espigas com palha. Após a colheita, as plantas foram cortadas rente ao solo e conduzidas para o laboratório para determinação da biomassa fresca e seca da parte aérea. A biomassa seca foi obtida após a secagem das plantas em estufa de ar de circulação forçada, à temperatura de $70^{\circ} \mathrm{C}$, até atingir peso constante.

Aos 100 DAP foi avaliada a produtividade de espigas de milho com e sem palha $(\mathrm{kg}$ $\left.\mathrm{ha}^{-1}\right)$, a produtividade de grãos $\left(\mathrm{kg} \mathrm{ha}^{-1}\right)$ e o peso de 100 grãos $(\mathrm{g})$, considerando-se seis plantas por subparcela.

As colheitas de milho verde (69 DAP) e seco (100 DAP) foram realizadas em áreas úteis das parcelas, descartando-se as linhas externas e 1,0 m das extremidades das linhas centrais (bordadura).

Os dados referentes às variáveis observadas foram submetidos à análise de variância pelo programa estatístico SISVAR (FERREIRA, 2014) e, quando significativas, as médias dos tratamentos foram submetidas à análise de regressão.

\section{RESULTADOS E DISCUSSÃO}

\subsection{MILHO VERDE}

De acordo com os resultados houve efeito significativo da interação lâmina x esterco, para as variáveis diâmetro do colmo, produtividade da biomassa fresca e seca da parte aérea e produtividade de espiga verde. Para a variável altura de planta não interação entre os fatores, porém houve efeito de lâmina e esterco isoladamente (Tabela 3). 
ISSN 2525-9075 on-line

Tabela 3 - Resumo da análise de variância com os quadrados médios para altura, diâmetro, biomassa fresca, biomassa seca e peso de espiga verde do milho BRS Gorutuba.

\begin{tabular}{lccrrrr}
\hline Fonte de variação & $\begin{array}{c}\text { Graus de } \\
\text { Liberdade }\end{array}$ & $\begin{array}{c}\text { Altura de } \\
\text { planta }\end{array}$ & $\begin{array}{c}\text { Diâmetro de } \\
\text { colmo }\end{array}$ & $\begin{array}{c}\text { Biomassa } \\
\text { fresca }\end{array}$ & $\begin{array}{c}\text { Biomassa } \\
\text { seca }\end{array}$ & \multicolumn{2}{c}{$\begin{array}{c}\text { Peso de espiga } \\
\text { verde }\end{array}$} \\
\hline Bloco & 2 & 0,00218 & 0,2308 & $1.051,484$ & 381,328 & $4.759,472$ \\
Lâmina (L) & 3 & $0,07821^{* *}$ & $2,9804^{*}$ & $2.611,701^{\text {ns }}$ & $3.869,236^{* *}$ & $341,146^{* *}$ \\
\hline Resíduo A & 6 & 0,00624 & 11,749 & $1,590,894$ & 106,918 & $4.759,472$ \\
\hline Esterco (E) & 1 & $0,20507^{* *}$ & $46,5931^{* *}$ & $322.300,104^{* *}$ & $40.950,938^{* *}$ & $341,146^{* *}$ \\
Interação L*E & 3 & $0,01353^{\text {ns }}$ & $3,1804^{*}$ & $4.538,3785^{* *}$ & $580,9757^{* *}$ & $475,9472^{*}$ \\
\hline Resíduo B & 8 & 0,00392 & 0,7013 & $4.802,552$ & 341,146 & $1.654,141$ \\
\hline Total & 23 & 0,03481 & 48,391 & $31.862,326$ & $4.759,472$ & $18.423,915$ \\
\hline ns= não significativo; *= significativo a 5\% e **=significativo a 1\% pelo teste F & & &
\end{tabular}

De acordo com a análise de variância a adição de esterco proporciona maior altura de plantas e, em relação às lâminas observa-se efeito significativo ( $\mathrm{p} \leq 0,01)$, ajustando-se equação linear. Nota-se que os valores de altura de plantas de milho tendem a aumentar com a maior disponibilidade hídrica no solo. $\mathrm{O}$ aumento da disponibilidade de água e nutrientes no solo favorece o desenvolvimento radicular, permitindo que as plantas realizem os processos metabólicos necessários ao seu crescimento (SOUZA et al., 2017). Os resultados corroboram os observados por Almeida (2016), que avaliando o comportamento da cultura do milho sob déficit e excesso hídrico, observou que os maiores valores em altura de plantas de milho foram encontrados nos tratamentos com excesso hídrico no ciclo total da cultura ou em fases fenológicas específicas e, por outro lado, as menores alturas foram observadas em plantas sob déficit.

Figura 1. Altura de planta de plantas de milho BRS Gorutuba em função de diferentes lâminas de água aos 69 DAP.

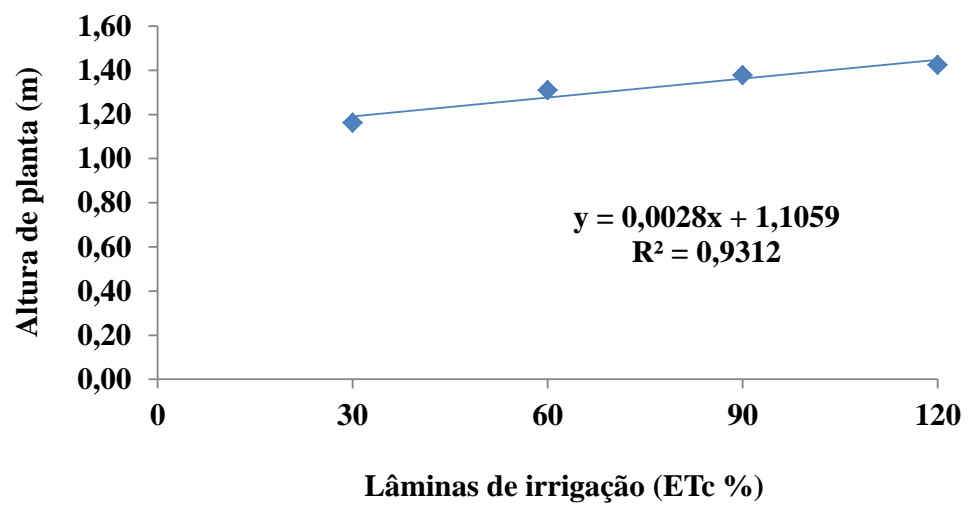

Para a variável diâmetro de colmo, observou-se efeito significativo $(\mathrm{p} \leq 0,05)$ da interação lâmina $\mathrm{x}$ esterco. Verifica-se, na Figura 2, que a presença de esterco caprino influência de forma positiva o diâmetro de colmo, com ajuste de equação linear com aumento da disponibilidade hídrica. Tal fato é justificado pela quantidade aplicada ser suficiente para crescimento máximo das plantas, permitindo maior expansão das células. 
Figura 2. Diâmetro de colmo de plantas de milho BRS Gorutuba em função de diferentes lâminas de irrigação, aos 69 DAP, na presença e ausência de esterco caprino.

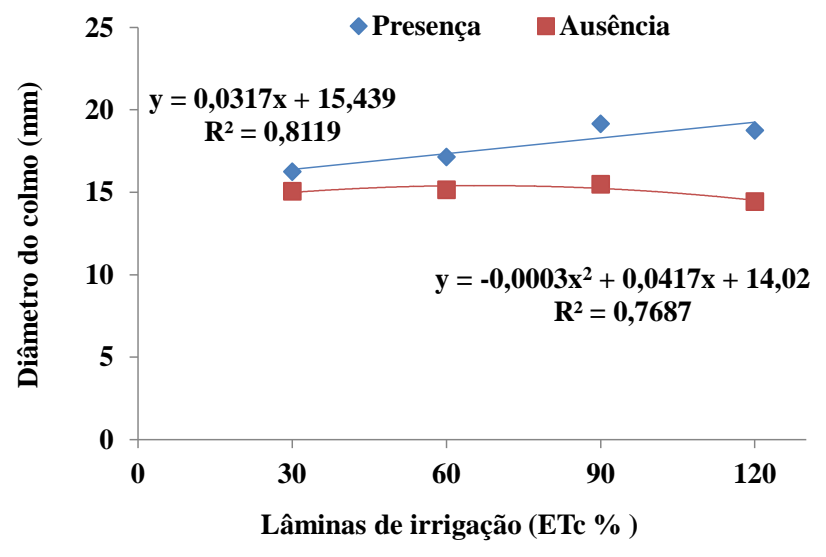

Nas Figuras 3 e 4 é possível observar o efeito quadrático positivo na presença de esterco em função das lâminas de água aplicadas para as produtividades de biomassa fresca e seca da parte aérea. A maior produtividade de biomassa fresca foi encontrada na lâmina de $90 \%$ da ETc, com 11.866,70 $\mathrm{kg} \mathrm{ha}^{-1}$ (Figura 3) e biomassa seca de 4.350,00 kg ha-1 (Figura 4) na presença de esterco. Tais resultados são relevantes, pois demonstram que é possível atingir elevadas produtividades de biomassa na cultura do milho utilizando-se lâminas de irrigação inferiores a $100 \%$ da ETc na presença de esterco caprino. Infere-se que o aumento na produtividade de biomassa fresca e seca está relacionado à disponibilidade hídrica e ao fornecimento de nutrientes que são liberados pelo esterco caprino, o qual além de disponibilizar macro e micronutrientes, facilita a capacidade de troca de cátions devido à presença da matéria orgânica. Souza et al. (2017) também atribuíram à presença de esterco caprino os acréscimos na biomassa fresca e seca da parte aérea de plantas de milho submetidas ao estresse hídrico, contudo, o comportamento foi linear ao contrário do observado no presente trabalho, que apresentaram comportamento quadrático.

Figura 3. Produtividade de biomassa fresca de plantas de milho BRS Gorutuba em função de diferentes lâminas de água aplicada, aos 69 DAP, na presença e ausência de esterco caprino.

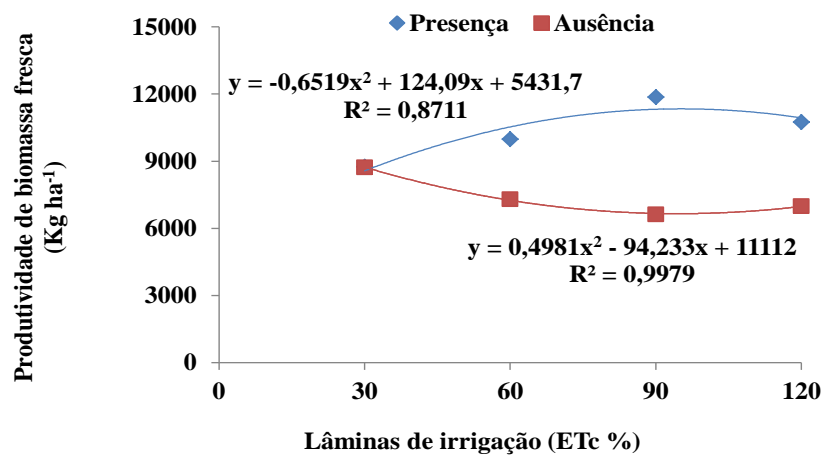


Figura 4. Produtividade de biomassa seca de plantas de milho BRS Gorutuba em função de diferentes lâminas de água, aos 69 DAP, na presença e ausência de esterco caprino.

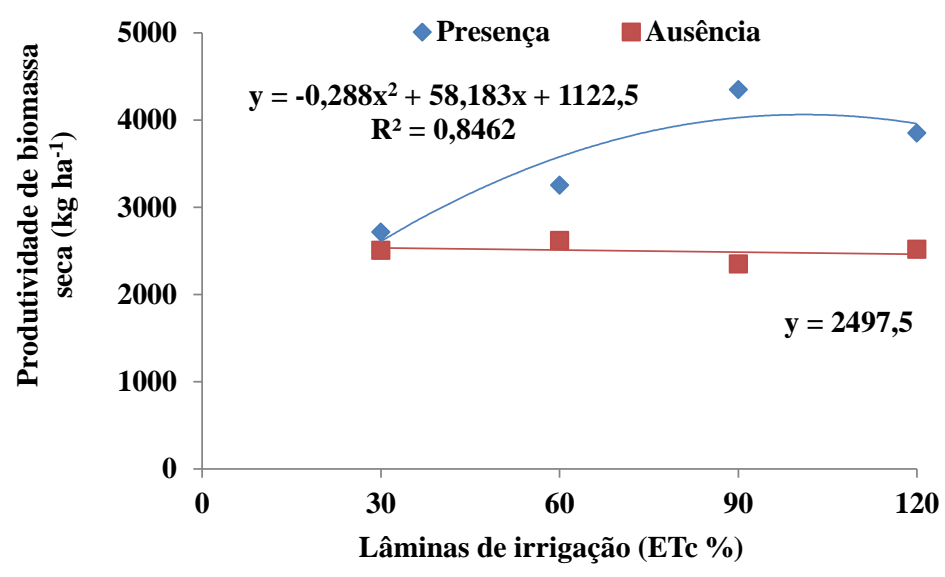

A ausência de esterco para o cultivo do milho, mesmo com o aumento das lâminas de água aplicada, é afetada, isso evidencia a importância da reposição de nutrientes advindo do esterco para a cultura, principalmente em solos com baixa fertilidade, como o utilizado nesse experimento (Tabela 1). Segundo Soro et al. (2015), os resultados da adubação orgânica na produção de grãos de milho têm demonstrado produtividade semelhante aos da adubação química equivalente, pois ao estudarem o uso de esterco de aves no cultivo do milho, verificaram impacto positivo no crescimento e desenvolvimento da cultura. No caso do esterco caprino, os resultados são promissores também, conforme observado por Melo et al. (2009) e Souza et al. (2017). Destaca-se ainda, que este insumo está presente nos currais, de praticamente todos os agricultores familiares, no qual seu uso, além de melhorar a eficiência econômica do cultivo do milho contribui para a sustentabilidade do sistema, uma vez que o mesmo pode repor os nutrientes retirados pelos cultivos ao longo dos anos.

De acordo com a análise de variância houve efeito significativo da interação lâmina $\mathrm{x}$ esterco para produtividade de espigas de milho verde com palha (Figura 5), ajustando-se equação linear, com incremento significativo na produtividade em função do aumento da disponibilidade de água e da presença de esterco. Esse resultado está relacionado possivelmente aos efeitos positivos dos fatores, uma vez que a disponibilidade hídrica favorece a absorção de nutrientes pelas plantas, principalmente em solos de baixa fertilidade.

Figura 5. Produtividade de espigas de milho verde com palha em função de diferentes lâminas de água, aos 69 DAP, na presença e ausência esterco caprino.

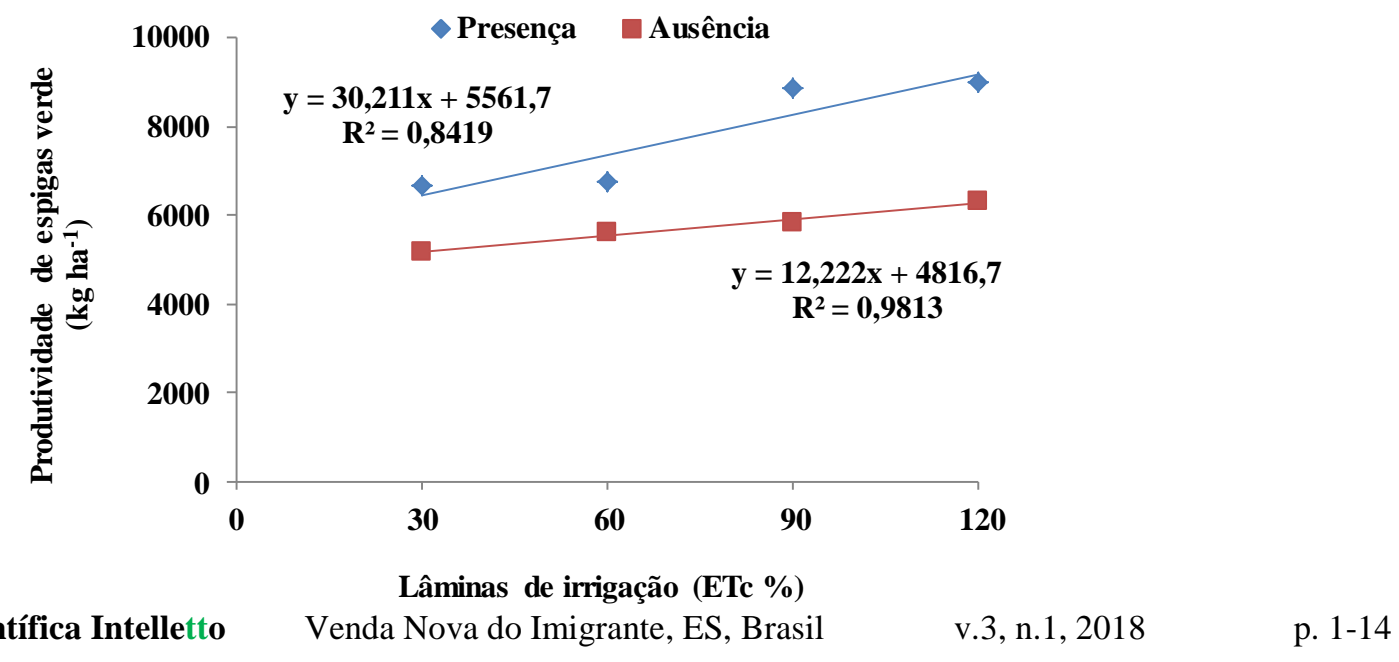


O manejo adequado e a determinação da lâmina de água a ser aplicada, sobretudo nas fases críticas da cultura, como florescimento e enchimento de grãos, são fatores importantes a serem considerados, pois, podem ocorrer reduções de produtividades, devido à falta ou excesso de água. Bergamaschi et al. (2004) destacam que para o milho obter elevados rendimentos é necessária a reposição adequada de água no período próximo ao pendoamentoespigamento, pois é uma fase crítica. Como observado no presente trabalho, menores lâminas de reposição reduziram a produtividade de espigas verde (Figura 5).

\subsection{MILHO SECO}

De acordo com os resultados da analise de variância foi possível observar que não houve efeito da interação para nenhuma das variáveis analisadas (Tabela 4). No entanto, houve efeito significativo ( $\mathrm{p} \leq 0,01)$, de lâminas para todas as variáveis e de efeito do esterco apenas para produtividade de espigas com palha e produtividade de grãos $(p \leq 0,05)$.

Tabela 4 - Resumo da análise de variância com os quadrados médios para produtividade de espigas com e sem palha, produtividade de grãos e peso de 100 grãos do milho BRS, Gorutuba.

\begin{tabular}{lcrrrr}
\hline $\begin{array}{c}\text { Fonte de } \\
\text { variação }\end{array}$ & $\begin{array}{c}\text { Graus de } \\
\text { Liberdade }\end{array}$ & $\begin{array}{c}\text { Produtividade de } \\
\text { espigas com palha }\end{array}$ & $\begin{array}{c}\text { Produtividade de } \\
\text { espigas sem palha }\end{array}$ & $\begin{array}{c}\text { Produtividade } \\
\text { de grãos }\end{array}$ & $\begin{array}{c}\text { Peso de 100 } \\
\text { grãos }\end{array}$ \\
\hline Bloco & 2 & $84,736,979$ & $77,278,646$ & $34,927,083$ & 74,827 \\
Lâmina (L) & 3 & $19171,6146^{*}$ & $11596,6146^{*}$ & $10838,5417^{*}$ & $129,9447^{*}$ \\
Resíduo A & 6 & $16,549,479$ & $9,903,646$ & $11,670,139$ & 59,657 \\
Esterco (E) & 1 & $11063,2813^{* *}$ & $7350,7813^{\text {ns }}$ & $11628,1250^{*}$ & $3,5979^{\text {ns }}$ \\
Interação L*E & 3 & $2257,0313^{\text {ns }}$ & $1700,7813^{\text {ns }}$ & $1417,7083^{\text {ns }}$ & $6,5678^{\text {ns }}$ \\
Resíduo B & 8 & $21,919,271$ & $17,945,313$ & $10,369,792$ & 45,980 \\
\hline Total & 23 & $60,876,234$ & $41,757,813$ & $36,514,803$ & 257,513 \\
\hline
\end{tabular}

$\mathrm{ns}=$ não significativo; $*$ = significativo a $5 \%$ e $* *=$ significativo a $1 \%$ pelo teste $\mathrm{F}$.

As lâminas de irrigação independente da presença esterco caprino proporcionaram ajuste linear para a variável produtividade de espigas de milho com palha (Figura 6), sendo a maior produtividade encontrada na lâmina de $120 \%$ da ETc, que representa uma adição de água de 559,41 mm durante o ciclo da cultura.

Figura 6. Produtividade de espiga de milho seca com palha BRS Gorutuba em função de diferentes lâminas de água aplicada, aos 100 DAP, na presença e ausência esterco caprino.

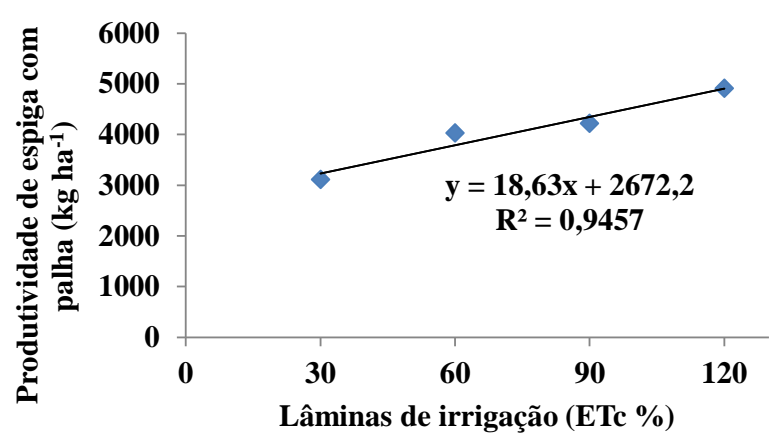


O comportamento da variável produtividade de espigas sem palha seguiu a mesma tendência da apresentada pela produtividade de espigas com palha, demostrando que a produtividade de milho aumenta com o aumento da quantidade de água aplicada (Figura 7).

De acordo com Albuquerque et al. (2008), a produtividade de espigas com palha é suficiente para inferir sobre os resultados de produtividade de espigas sem casca, pois em estudo realizado por estes autores constatou-se correlação alta entre as duas variáveis.

Figura 7. Produtividade de espiga de milho seca sem palha BRS Gorutuba em função de diferentes lâminas de água aplicada, aos 100 DAP, na presença e ausência esterco caprino.

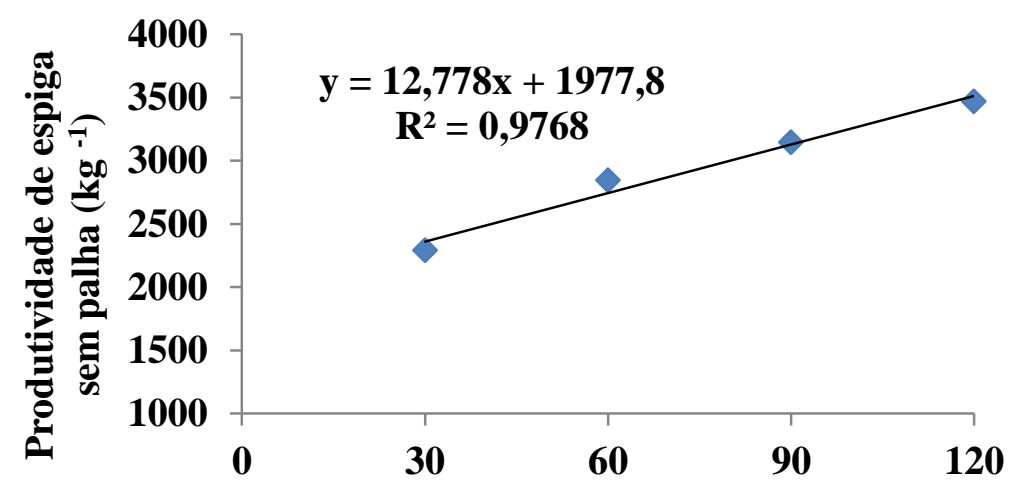

Lâminas de irrigação (ETc \%)

De acordo com a análise de variância houve efeito significativo $(\mathrm{p} \leq 0,05)$ para lâmina e esterco, isoladamente, em relação à variável produtividade de grãos, ajustando-se equação linear, evidenciando que a produtividade do milho independe da interação dos fatores. $\mathrm{O}$ modelo ajustado indica aumento de produtividade com aplicação de água de até $559,41 \mathrm{~mm}$ (L120), alcançando $3.977,78 \mathrm{~kg} \mathrm{ha}^{-1}$ de grãos (Figura 8). Convém ressaltar que a cultivar utilizada, apesar de ser recomendada para agricultura dependente de chuva, com baixo custo de produção, responde em produtividade ao aumento de lâminas.

Depreende-se, também, que a cultivar BRS Gorutuba apresentou potencial em produzir com baixa quantidade de água $(139,85 \mathrm{~mm})$ com produtividade de $2.288,89 \mathrm{~kg} \mathrm{ha}^{-1}$, valor este superior à média de produtividade observada na maioria dos estados do Nordeste, onde dificilmente ultrapassa $1.000 \mathrm{~kg} \mathrm{ha}^{-1}$ (CONAB, 2017) em áreas dependentes de chuva (Figura 8). Os valores de produtividade do milho BRS Gorutuba encontrados foram de 2.888,89; 3.422,22; 3.533,33; e 3.977,78 $\mathrm{kg} \mathrm{ha}^{-1}$ para as lâminas de 139,85; 279,71; 419,56; e $559,41 \mathrm{~mm}$, respectivamente. Os resultados de produtividade de grãos estão bem acima do encontrado por Brito et al. (2008) para o milho BRS Catingueiro, em cultivo tradicional dependente de chuva, que foi de $362,0 \mathrm{~kg} \mathrm{ha}^{-1} \mathrm{em}$ condições de $322,8 \mathrm{~mm}$ de água de chuva. Esta diferença pode estar relacionada com a irregularidade de chuvas no tempo e no espaço, o que não ocorre com o uso da irrigação. A produtividade obtida com a lâmina de irrigação de $559,41 \mathrm{~mm}$ está acima dos valores médios de produtividade de $3.260 \mathrm{~kg} \mathrm{ha}^{-1}$ do Brasil e abaixo da produtividade média de $4000 \mathrm{~kg} \mathrm{ha}^{-1}$ dos Estados Unidos, sendo esse o maior produtor mundial (FORNASIERI FILHO, 2007). 
Figura 8. Produtividade de grãos de milho BRS Gorutuba em função de diferentes lâminas de água aplicada, aos 100 DAP, na presença e ausência esterco caprino.

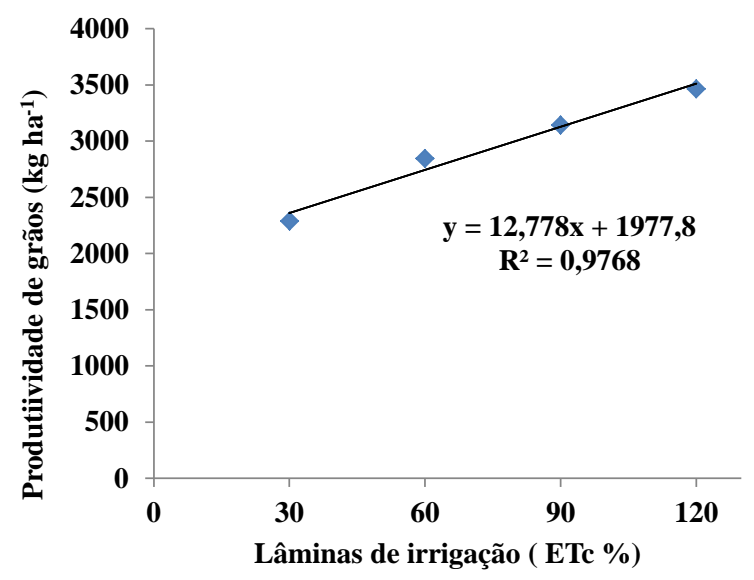

O déficit de umidade no solo durante o ciclo de cultivo pode afetar gravemente o rendimento da cultura, especialmente se ocorrer no início e durante a sua fase de floração, o que geralmente acontece em áreas dependentes de chuva devido ao veranico ocorrido entre os eventos de precipitação. Assim, o agricultor deve planejar seus cultivos de acordo com a água disponível em sua propriedade, de forma a utilizar o recurso hídrico para a irrigação nos períodos mais críticos, optando-se por sistemas de irrigação que contemplem a eficiência no uso da água e a sustentabilidade do sistema produtivo. Dessa forma, os agricultores podem se valer das tecnologias de captação e armazenamento de água de chuva (barragem subterrânea, barreiro, cisterna calçadão, tanque de pedra, entre outras) para a irrigação do milho nos períodos de estiagem prolongada.

Outra variável analisada foi o peso de 100 grãos de milho que se apresentou diferença significativa em função das lâminas de irrigação utilizada com efeito linear, onde maiores reposições hídricas possibilitaram maior peso dos grãos (Figura 9).

Figura 9. Peso de 100 grãos (b) de milho BRS Gorutuba em função de diferentes lâminas de água aplicada aos 100 DAP.

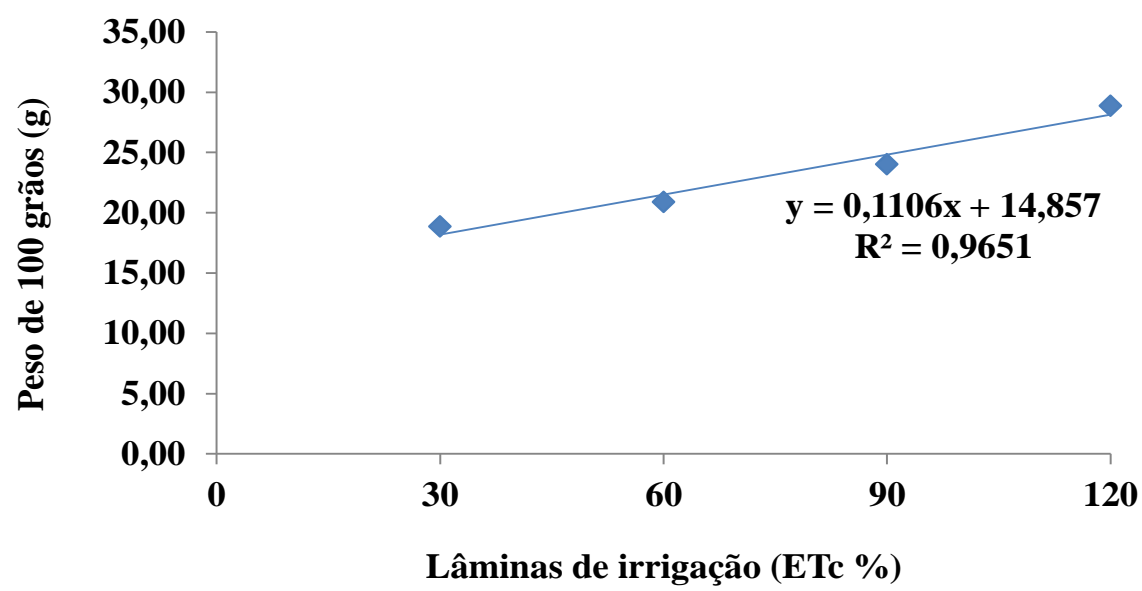


Considerando que no semiárido a disponibilidade de água é um fator limitante e que a cultura do milho tem papel importante na agricultura familiar da região, os resultados encontrados são relevantes ao se referirem à aplicação de menores lâminas de irrigação com a utilização de esterco caprino para se alcançar produtividades satisfatórias com a cultivar de milho BRS Gorutuba, uma vez que muitos agricultores familiares dispõem de tecnologias de captação e armazenamento de água de chuva para efetuar as irrigações e, também, dispõe de esterco caprino em suas propriedades.

\section{CONCLUSÃO}

A aplicação de lâminas de irrigação e a adubação com esterco caprino influenciaram de forma positiva os componentes de crescimento e de produção da cultivar de milho BRS Gorutuba, apresentando valores de produtividade superiores aos encontrados em áreas dependentes de chuva no semiárido.

\section{REFERÊNCIAS}

ALBUQUERQUE, C. J. B. et al. Produtividade de híbridos de milho verde experimentais e comerciais. Bioscience Journal, v. 24, n. 2, p.69-76, 2008.

ALLEN, R. G. et al. Evapotranspiración del cultivo: guías para la determinación de los requerimientos de agua de los cultivos. Roma: FAO, 2006. (Estudio FAO Riego y Drenaje, 56).

ALMEIDA, B. M. Déficit e excesso hídrico na cultura do milho (Zea mays L.) em ambiente protegido. 2016. 124p. Tese (Doutor em Ciências: Engenharia de Sistemas Agrícolas) - Escola Superior de Agricultura "Luiz de Queiroz", Piracicaba: ESALQ, 2016.

ARGAW, A. Organic and inorganic fertilizer application enhances the effect of Bradyrhizobium on nodulation and yield of peanut (Arachis hypogea L.) in nutrient depleted and sandy soils of Ethiopia. International Journal of Recycling of Organic Waste in Agriculture, v. 6, n. 3, p. 219-231, 2017.

BERGAMASCHI, H. et al. Distribuição hídrica no período crítico do milho e produção de grãos. Pesquisa Agropecuária Brasileira, v. 39, n. 9, p.831-839, 2004.

BRITO, L. T. L. et al. Perdas de solo e de água em diferentes sistemas de captação in situ no Semiárido brasileiro. Engenharia Agrícola, Jaboticabal, v.28, n.3, p.507-515, 2008.

CARVALHO, H. W. L. et al. BRS Gorotuba: variedade de milho superprecoce. Aracaju: Embrapa Tabuleiros Costeiros, 2010. 4 p. (Embrapa Tabuleiros Costeiros. Comunicado Técnico, 104).

CONAB. COMPANHIA NACIONAL DE ABASTECIMENTO. Acompanhamento da safra brasileira de grãos, v. 5- Safra 2017/18. Acessado em 21 de novembro de 2017. Disponível em: <http://www.conab.gov.br/OlalaCMS/uploads/arquivos/17_11_23_15_06_58_boletim_de_gr ao_-_2o_lev_2017.pdf>.

DONAGEMA, G. K. et al. (Org.). Manual de métodos de análise de solo. 2. ed. rev. Rio de Janeiro: Embrapa Solos, 2011. 
DOORENBOS, J.; KASSAM, A. H. Efeito da água no rendimento das culturas. Campina Grande: UFPB, 1994. 306p. (Estudos FAO: Irrigação e Drenagem, 33).

FERREIRA, D. F. Sisvar: a guide for its bootstrap procedures in multiple comparisons. Ciência e Agrotecnologia, Lavras, v. 38, n. 2, p. 109-112, 2014.

FREITAS, M. S. C. et al. Decomposição e liberação de nutrientes de estercos em função da profundidade e do tempo de incorporação. Revista Semiárido de Visu, v. 2, n. 1, p. 150-161, 2012.

FORNASIERI FILHO, D. Manual da cultura do milho. 1 ed. Jaboticabal: Funep, 2007. 576p. IBGE. INSTITUTO BRASILEIRO DE GEOGRAFIA E ESTATÍSTICA. Produção da pecuária municipal - PPM. Acessado em 29 de novembro de 2017. Disponível em: <https://www.ibge.gov.br/estatisticas-novoportal/economicas/agricultura-e-pecuaria/9107producao-da-pecuaria-municipal.html? \&t=downloads $>$.

KATERJI, N. et al. Water use efficiency of crops cultivated in the Mediterranean region: review and analysis. European Journal of Agronomy, v. 28, n. 4, p. 493-507, 2008.

MELO, R. F. et al. Avaliação do uso de adubo orgânico nas culturas de milho e feijão caupi em barragem subterrânea. Revista Brasileira de Agroecologia, v. 4, n. 2, p. 1264-1267, 2009.

MOURA, M. S. B. et al. Clima e água de chuva no Semi-Árido. In: BRITO, L. T. L. et al. (Ed.). Potencialidades da água de chuva no Semi-Árido brasileiro. Petrolina: Embrapa Semi-Árido, 2007. cap. 2, p. 37-59.

PEREIRA, D. C. et al. Adubação orgânica e algumas aplicações agrícolas. Revista Varia Scientia Agrárias, v. 3, n. 2, p.159-174, 2013.

PIZARRO, F. Riegos localizados de alta freqüência-goteo-microaspersor-exudacion. 3.ed. Madrid: Mundi-Prensa, 1996. 513p.

RONG, Y. et al. Effect of chemical and organic fertilization on soil carbon and nitrogen accumulation in a newly cultivated farmland. Journal of Integrative Agriculture, v. 15, n. 3, p. 658-666, 2016.

SADRAS, V. O. et al. Status of water use efficiency of main crops. Rome: FAO, 2011, 41p. (SOLAW Background Thematic Report, TR07).

SORO, D. et al. Impact of organic fertilization on maize (Zea mays L.) production in a ferralitic soil of centre - West Côte D'ivoire. Journal of Experimental Biology and Agricultural Sciences, v. 3, n. 6, 2015.

SOUZA, F. M. et al. Crescimento inicial do milho sob doses de esterco caprino e disponibilidade de água no solo. Revista Verde de Agroecologia e Desenvolvimento Sustentável, v. 12, n. 2, p. 241-245, 2017. 
SOUZA, L. S. B. et al. Determinação do coeficiente de cultura do milho (Zea mays L.) sob condições de semiárido brasileiro. In: CONGRESSO BRASILEIRO DE METEOROLOGIA, 16. 2010, Belém, PA. A Amazônia e o clima global. Anais... Belém: SBMET, 2010. 1 CDROM.

ZHUO, L.; HOEKSTRA, A. Y. The effect of different agricultural management practices on irrigation efficiency, water use efficiency and green and blue water footprint. Frontiers of Agricultural Science and Engineering, v. 4, n. 2, p.185-194, 2017.

Recebido para publicação: 28 de dezembro de 2017

Aprovado: 16 de março de 2018. 